\title{
Transarticular invasion of primary bone tumors abutting the sacroiliac joint: an MRI study in 128 patients
}

\section{Lei Ding}

Sun Yat-sen University First Affiliated Hospital

Jun-qiang Yin

Sun Yat-sen University First Affiliated Hospital

Fang-ling Zhang

Sun Yat-sen University Affiliated Stomotological Hospital

Yong-qian Wang

Sun Yat-sen University First Affiliated Hospital

Chang-ye Zou

Sun Yat-sen University First Affiliated Hospital

Zhenhua Gao ( $\nabla$ Gzhh_sysu@163.com )

Sun Yat-sen University First Affiliated Hospital

Research article

Keywords: sacroiliac joint, bone tumors, transarticular invasion, MRI

Posted Date: September 25th, 2019

DOI: https://doi.org/10.21203/rs.2.14776/v1

License: (9) (i) This work is licensed under a Creative Commons Attribution 4.0 International License.

Read Full License 


\section{Abstract}

Background: To investigate magnetic resonance imaging (MRI) manifestation of transarticular invasion of primary bone tumors abutting the sacroiliac joint and to compare the transarticular invasion incidences and transarticular routes of primary bone tumors in different locations, of different pathological types, and of different pathological grades.

Methods: We conducted a retrospective analysis of clinical and MRI data for 128 patients (80 males, 48 females; mean age, 32.5 years; age range, 4-74 years) treated in our hospital from January 2004 to December 2015. The primary tumors located in the ilium in 87 patients and the sacrum in 41 patients. The diagnosis of the patients was confirmed by surgical findings and pathological examination. Based on pathology grading systems, the tumors were divided into a high-grade malignant tumor group (Group 1), low-grade malignant tumor group (Group 2) and intermediate tumor group (Group 3). Transarticular invasion routes included 3 types: invasion across the ligamentous portion (Type 1), across articular cartilage (Type 2) and across periarticular tissue (Type 3). For tumors with coexistence of multiple types of invasion, each type was counted once.

Results: Transarticular invasion of primary bone tumors abutting the sacroiliac joint were diagnosed in 33 patients (25.8\%). Group 1 included 15 patients (51.7\%) with conventional osteosarcoma and 7 patients (43.8\%) with Ewing's sarcoma. Group 2 included 4 patients (11.4\%) with central chondrosarcoma and 1 patient $(7.7 \%)$ with chordoma. Group 3 included 4 patients (20.0\%) with giant cell tumor of bone, 1 patient $(16.7 \%)$ with chondroblastoma and 1 patient $(11.1 \%)$ with aneurysmal bone cyst. Transarticular invasion incidences were not significantly different between primary iliac and sacral tumors $(\chi 2$ value $=$ $2.39, P>0.05)$. Transarticular invasion incidences were not significantly different between group 2 and group $3(X 2$ value $=0.32, P>0.05)$. However, the transarticular invasion incidences were significantly different between group 2 or 3 and group $1(P<0.01)$. Of the 33 patients with transarticular invasion, the invasion types included 31 type 1, 15 type 2 and 5 type 3 invasions. A significant difference was observed between different invasion types $(P<0.01)$. By contrast, the different invasion types were not related to different pathological grades $(P>0.05)$.

Conclusions: MRI is a highly sensitive method to diagnose transarticular invasion of primary bone tumors abutting the sacroiliac joint. The transarticular invasion incidence is not significantly different between primary iliac and sacral tumors. Tumor invasion across the sacroiliac joint can be present in both malignant and intermediate bone tumors, but predominantly in osteosarcoma and Ewing's sarcoma. Transarticular invasion across the ligamentous portion is more common. No significant difference is evident between the 3 types of invasion in the groups with different pathological grades, suggesting that the transarticular invasion types are not related to the malignant degree of tumor.

\section{Background}


Due to the deep location of a primary bone tumor abutting the sacroiliac joint, the tumor may invade the sacroiliac joint or even cross it at the time of diagnosis. Preoperative definite diagnosis of transarticular invasion of the sacral or iliac tumor may have guiding significance in the determination of the surgical regimen ${ }^{[1]}$. Imaging studies of pelvic bone tumors invading the sacroiliac joint or across the sacroiliac joint have been rarely reported in the literature ${ }^{[1-4]}$. A review of the literature on bone tumor invasion of the sacroiliac joint or across the sacroiliac joint raises several scientific questions for further study: (1) What is the accuracy of magnetic resonance imaging (MRI) in the diagnosis of tumor invasion across the sacroiliac joint? (2) The sacroiliac joint includes the anterior-inferior synovial portion and posteriorsuperior ligamentous portion. Are the incidences or types of transarticular invasion similar between iliac and sacral tumors abutting the sacroiliac joint? (3) What are the differences in the incidences or types of transarticular invasion between tumors with different pathological types or malignancies? Therefore, common primary bone tumors abutting the sacroiliac joint were selected as the target in this study. Based on surgical findings and postoperative pathological examination, the accuracy of MRI for revealing transarticular invasion of primary bone tumors abutting the sacroiliac joint was evaluated. The differences in the incidence or types of primary bone tumors with different original locations or pathological types or grades were compared. The possible reasons for the differences are discussed.

\section{Methods}

\section{Patients}

Clinical and MRI data for 128 patients treated in our hospital from January 2004 to December 2015 were collected and reviewed. The diagnosis of these patients was confirmed by surgical findings and pathological examination. The primary tumor was in the ilium in 87 patients and in the sacrum in 41 patients. Eighty men and 48 women with an average age of 32.5 years (range: 4-74 years) were included in this study. A total of 29 patients were diagnosed with conventional osteosarcoma, 16 with Ewing's sarcoma, 35 with central chondrosarcoma, 13 with chordoma, 20 with giant cell tumor of the bone (6 of which were complicated with secondary aneurysmal bone cysts), 6 with chondroblastoma, and 9 with primary aneurysmal bone cyst. Based on pathology grading systems, these tumors were divided into the high-grade malignant tumor group (Group 1, 45 patients with conventional osteosarcoma or Ewing's sarcoma), the low-grade malignant tumor group (Group 2, 48 patients with central chondrosarcoma or chordoma) and the intermediate tumors group (Group 3, 35 patients with giant cell tumor of the bone, chondroblastoma or aneurysmal bone cyst). This study was approved by the Institutional Ethics Committee of the First Affiliated Hospital of Sun Yat-Sen University, and the need for signed informed consent was waived.

\section{Examination method}

Siemens Magnetom Vision 1.5 T and Magnetom Trio Tim 3.0T whole-body superconducting MRI scanners (Germany) were used for preoperative plain and enhanced MRI scans (including routine 
transverse, sagittal, and coronal views) of all patients. The MRI sequence included a T1-weighted conventional spin echo sequence $(T R=450-600 \mathrm{~ms}, T E=12-14 \mathrm{~ms}), T 2$-weighted fast spin echo sequence $(T R=3000-4500 \mathrm{~ms}, T E=90-120 \mathrm{~ms})$, $T 2 \mathrm{Wl}$ with fat suppression $(\mathrm{TR}=3000-4500 \mathrm{~ms}, \mathrm{TE}=$ 90-120 ms), enhanced T1WI (TR $=450-600 \mathrm{~ms}, \mathrm{TE}=12-14 \mathrm{~ms})$, and enhanced T1WI with fat suppression ( $T R=450-600 \mathrm{~ms}, \mathrm{TE}=12-14 \mathrm{~ms}$ ). Gadolinium-diethylenetriamine pentaacetic acid (GdDTPA) at a concentration of $0.5 \mathrm{mmol} / \mathrm{L}$ was intravenously administered at a dose of $0.2 \mathrm{ml} / \mathrm{kg}$ and at a rate of $1.0 \mathrm{ml} / \mathrm{s}$ for enhanced scans. The slice thickness was $5-8 \mathrm{~mm}$, and the interlayer spacing was $0.5-0.8 \mathrm{~mm}$.

\section{Evaluation of the imaging studies}

In this study, a sacral or iliac tumor with a minimum length from the tumor margin to the ipsilateral sacroiliac joint surface of less than $2 \mathrm{~cm}$ was defined as a bone tumor abutting the sacroiliac joint ${ }^{[4]}$. The transarticular invasion of a bone tumor was defined as invasion by the sacral or iliac tumor of the opposite bone of the joint to cause bone destruction ${ }^{[1-4]}$. The MRI images were reviewed by 2 or more radiologists specializing in bone oncology who made the final agreement about the diagnosis. The types of transarticular invasion of a bone tumor abutting the sacroiliac joint include (1) transarticular invasion across the ligamentous portion posterior to the sacroiliac joint (i.e., invasion across the ligamentous potion) (Type 1, Figure 1); (2) transarticular invasion via direct destruction of the cartilage anterior-inferior to the sacroiliac joint, into the articular space, and then to the opposite side of the joint (i.e., invasion across the articular cartilage) (type 2, Figure 2); and (3) transarticular invasion across the muscles and ligaments around the sacroiliac joint (i.e., invasion across the periarticular tissue) (type 3, Figure 3). For tumors in which 2 or more types of transarticular invasion coexisted (including invasion across the entire sacroiliac joint, i.e., Type $1+$ Type 2; transarticular invasion across the entire joint and periarticular tissues, i.e., Type 1 + Type 2 + Type 3 ), each type was separately counted once (Figure 4).

\section{Pathological diagnostic criteria}

Transarticular invasion and its types were confirmed by surgical findings and pathological examination. The invasion types included single-type invasion, such as invasion across the ligamentous portion, articular cartilage or periarticular soft tissue of the sacroiliac joint, and multiple-type combinations of invasion to cause destruction of the opposite bone.

\section{Statistical analysis}

SPSS 17.0 statistical software was used for data analysis. The chi-squared test for count data was used to compare differences in the transarticular invasion incidence and types among primary bone tumors in different locations, of different pathological types, and of different pathological grades. A P value less than 0.05 was considered statistically significant. 


\section{Results}

\section{MRI diagnostic accuracy for the transarticular invasion of primary bone tumors abutting the sacroiliac joint}

Bone tumors abutting the sacroiliac joint can cause ipsilateral bone destruction, which may show abnormal MRI or CT signal intensity. The tumor tissue can invade into the sacroiliac joint or spread along its surrounding structures to the contralateral bone. The contralateral bone is then destroyed and replaced with tumor tissue. In this study, 33 of 128 (25.8\%) patients with primary bone tumors abutting the sacroiliac joint presented with transarticular invasion (Table 1), which was $100 \%$ consistent with the surgical findings and pathological examination.

\section{Comparison of transarticular invasion incidence in different locations of the sacroiliac joint}

Of 128 patients with primary bone tumors abutting the sacroiliac joint, 87 patients were diagnosed as iliac tumors, with $26(29.9 \%)$ patients presenting with invasion across the sacroiliac joint; 41 patients had sacral tumors, with $7(17.1 \%)$ patients presenting with transarticular invasion. In general, the incidences of the primary bone tumors did not significantly differ between the sacrum and the ilium ( $\chi 2$ value $=2.39$, $P>0.05)$. In this study, 93 patients had malignant bone tumors, and 35 patients had intermediate bone tumors. In Group 1, 43 and 2 patients had iliac and sacral tumors, respectively. These patients accounted for $46.2 \%$ and $2.2 \%$ of all patients with malignant tumors. The difference in transarticular invasion incidence was not compared between these groups because their proportions were not compatible. In Group 2, similar numbers of patients had iliac and sacral tumors, with 26 and 22 patients, respectively ( $\chi 2$ value $=0.04, P>0.05)$. In Group 3, 18 patients had iliac tumors, and 17 patients had sacral tumors $(X 2$ value $=0.14, P>0.05)$. No significant differences were observed in the transarticular invasion incidence of tumors in different locations in Groups 2 and 3.

\section{Comparison of the transarticular invasion incidence in different pathological types of tumors}

The overall incidence of transarticular invasion was $29.0 \%$ (27/93) in the 4 types of malignant bone tumors (Groups 1 and 2). The transarticular invasion incidence was similarly high in the patients with conventional osteosarcoma (51.7\%) and those with Ewing's sarcoma (43.8\%) ( $X 2$ value $=0.26, P>0.05$ ); The transarticular invasion incidence was similarly low in the patients with central chondrosarcoma $(11.4 \%)$ and those with chordoma $(7.7 \%)(X 2$ value $=0.02, P>0.05)$. The overall incidence of transarticular invasion was $17.1 \%(6 / 35)$ in the 3 types of intermediate bone tumors (Group 3$)$. The transarticular invasion incidences were not significantly different $(\chi 2$ value $=0.25, P>0.05)$ between the patients with the 3 types of intermediate tumors and those with tumor-like lesions. 


\section{Comparison of the transarticular invasion incidence in different pathological grades}

The overall incidence of transarticular invasion differed significantly among the pathological grades (different groups) $(X 2$ value $=19.84, P<0.01$ ). The transarticular invasion incidence did not differ significantly between Group 2 and Group 3 ( $\chi 2$ value $=0.32, P>0.05$ ), but the transarticular invasion incidences in Group 1 and Group 2 were both significantly different from that in Group $3(P<0.01)$ (Table 2).

\section{Comparison of transarticular invasion types in primary bone tumors abutting the sacroiliac joint.}

The transarticular invasion type and occurrence number in the 33 patients with primary bone tumors abutting the sacroiliac joint are shown in Table 3 and Table 4. Table 3 shows that type 1 (across the ligamentous potion) and type $1+$ type 2 (across the entire sacroiliac joint) were common types of transarticular invasion, whereas type 2 (across the articular cartilage) or type 3 (across the periarticular tissue) was rare. Of 13 patients with chordoma, only one patient presented with transarticular invasion across the periarticular tissue.

The statistical analysis results in Table 4 further demonstrate that the overall incidences of transarticular invasion of primary bone tumors were significantly different among type 1 (across the ligamentous portion), type 2 (across the articular cartilage) and type 3 (across the periarticular tissue) invasion ( $\chi 2$ value $=41.74, P<0.01)$. Further pairwise comparison showed statistic differences between the three types of transarticular invasion ( $\chi 2$ values and corresponding $P$ values were as follows: $\chi 2$ value $=18.37$, $P<0.01 ; \chi 2$ value $=41.31, P<0.01 ; \chi 2$ value $=7.17, P<0.01)$, suggesting that the transarticular invasion incidences differed among the 3 types: transarticular invasion of bone tumors abutting the sacroiliac joint across the ligamentous portion was the most common type, followed by across the articular cartilage and, finally, across the periarticular tissue. The incidences of the 3 types of transarticular invasion were not significantly different $(P>0.05)$ among the three groups. These results suggest that the transarticular invasion type is not associated with tumor benignity and malignancy or the degree of malignancy.

\section{Discussion}

\section{Value of imaging study assessment of transarticular invasion of primary bone tumors abutting the sacroiliac joint}


Among imaging techniques (X-ray, CT, MRI and radionuclide scans) for the assessment of bone tumors, MRI has unique advantages with respect to showing the range of intramedullary and surrounding soft tissue invasion of the bone tumor, invasion of the adjacent joints and bone metastasis. Abnormal signal changes on MRI can not only clearly reveal the location, size and involved range of bone tumors abutting the sacroiliac joint but also clearly show that a tumor destroying the ipsilateral cortical bone invades the contralateral bone of the joint across different structures of the sacroiliac joint. According to the literature, the sensitivity and specificity of MRI are $100 \%$ and $92 \%[2,4]$, respectively, if a strict definition of transarticular invasion of the bone tumor abutting the sacroiliac joint is used. In this study, 33 of 128 patients with primary tumors and tumor-like lesions abutting the sacroiliac joint presented with transarticular invasion in MRI studies, were all confirmed by surgical findings and pathological examination. These results indicate that MRI can accurately indicate transarticular invasion of a bone tumor abutting the sacroiliac joint with very high sensitivity.

\section{Comparison of transarticular invasion incidence in different locations}

The transarticular incidence of primary bone tumors was higher in the ilium than in the sacrum $(29.9 \% \mathrm{vs}$. $17.1 \%)$, but this difference was not statistically significant $(P>0.05)$. In Group 1 , significantly more patients with iliac lesions had transarticular invasion than those with sacral lesions. This group may be primarily responsible for the difference in the transarticular invasion incidences of iliac and sacral tumors. In Groups 2 and 3, the transarticular invasion incidences of iliac and sacral lesions did not differ significantly $(P>0.05)$. This study demonstrated that transarticular invasion of iliac and sacral tumors is not associated with the anatomical structure, i.e., the thinner iliac cartilage compared with the sacral cartilage, but is mainly associated with the degree of malignancy.

\section{Comparison of transarticular invasion incidence by different pathological type and grade}

In this study, the incidence of transarticular invasion was highest in Group 1 (conventional osteosarcoma and Ewing's sarcoma). The incidences of conventional osteosarcoma and Ewing's sarcoma were similar. The transarticular invasion incidence was lower in well-differentiated central chondrosarcoma. This finding is consistent with the biological characteristics of tumor malignancy and invasion. In this study, $27(29.0 \%)$ of 93 patients with malignant bone tumors appeared with transarticular invasion. This incidence is similar to the value of $29.4 \%(15 / 51)$ reported in the literature ${ }^{[2,4]}$. The transarticular invasion incidence reached $51.7 \%$ (15/29) in patients with osteosarcoma, also similar to the incidence of $53.8 \%$ $(7 / 13)$ reported in the literature ${ }^{[4]}$. However, the transarticular invasion incidence in patients with chondrosarcoma or Ewing's sarcoma obviously differed from that in the literature. Ozaki et al. reported in two studies ${ }^{[2,4]}$ that the transarticular invasion incidence of chondrosarcoma was $47.1 \%(8 / 17)$ and 
$46.7 \%(7 / 15)$, whereas the transarticular invasion incidence of Ewing's sarcoma was $4.3 \%(1 / 23)$ and $8.7 \%(2 / 23)$. In this study, the transarticular invasion incidence of chondrosarcoma and Ewing's sarcoma was $11.4 \%(4 / 35)$ and $43.8 \%(7 / 16)$, respectively. These incidences are obviously different from those in the literature. Other studies related to the transarticular incidence of Ewing's sarcoma are case reports or had small sample sizes ${ }^{[5-7]}$. These discrepancies may be attributable to differences in inclusion criteria. First, Ozaki's study only included patients with transarticular invasion of the primary iliac tumor, whereas the present study included patients with transarticular invasion of primary iliac and sacral tumors.

Second, the study by Ozaki, et al ${ }^{[2]}$ did not include patients with tumor margins $2 \mathrm{~cm}$ away from the joint surface, but these patients were included in their subsequent studies ${ }^{[4]}$. Next, patients with high-grade chondrosarcoma accounted for $80 \%$ of all patients with chondrosarcoma in the studies ${ }^{[2,4]}$ by Ozaki et al, whereas patients with low-grade chondrosarcoma were predominant in the current study. Hence, the degree of malignancy of chondrosarcoma is mainly attributable to the incidence of transarticular invasion.

The transarticular incidence of chordoma has not been reported. In this study, the transarticular incidence of chordoma was low, only $7.7 \%(1 / 13)$. This finding may be associated with the low-grade malignant nature of chordoma, which is less invasive. In addition, chordoma is usually located in the midline of the lower sacrum ${ }^{[8]}$, distant from the sacroiliac joint.

Few cases of transarticular invasion of intermediate bone tumors across the sacroiliac joint have been reported in the literature ${ }^{[3]}$. The transarticular invasion incidence has not been discussed. Of 35 patients with intermediate bone tumors abutting the sacroiliac joint in this study, only $6(17.1 \%)$ presented with transarticular invasion, including 4 (20\%) patients with giant cell tumor of bone, 1 (16.7\%) patient with chondroblastoma and $1(11.1 \%)$ patient with aneurysmal bone cyst. These results indicate that intermediate bone tumors are somewhat aggressive but the transarticular invasion incidence across the sacroiliac joint was significantly lower than that of highly malignant bone tumor.

\section{Comparison of transarticular invasion incidence between different invasion types of primary bone tumors abutting the sacroiliac joint}

Of 33 patients with tumor invasion across the sacroiliac joint, although a few patients showed involvement of two or more invasion types, but the statistical results after patients were sub-grouped showed differences in incidence among the 3 types of transarticular invasion of primary bone tumors, i.e., invasion across the ligamentous portion, the articular cartilage and the periarticular tissue. Invasion across the ligamentous portion was most common, followed by across the articular cartilage and, finally, across the periarticular tissue. In addition, the incidences of the 3 types of invasion were not associated with benignity and malignancy or the malignant degree of a tumor. 
Transarticular invasion of primary bone tumors across articular cartilage is usually complicated by invasion across the ligamentous portion. Isolated invasion across the articular cartilage is very rare. These findings are consistent with those from the previous literature ${ }^{[2,4]}$, indicating that the ligamentous portion is vulnerable to invasion of a bone tumor near the sacral iliac joint and that cartilage may prevent tumor invasion to some extent. The mechanism of tumor invasion prevention by cartilage may be related to the following factors. $\otimes$ There are no blood vessels in the articular cartilage. Thus, a direct anatomical basis and blood supply for tumor invasion and tumor cell growth are lacking ${ }^{[8]}$. $\otimes$ Cartilage cells produce a substance to inhibit tumor angiogenesis ${ }^{[9]}$ and collagenase activity ${ }^{[10-12]}$. In addition, the isolated invasion of primary bone tumors across the periarticular tissue is rare. Of 13 patients with chordoma, only 1 patient presented with transarticular invasion across the periarticular tissue. A possible explanation is that chordoma is usually located in the midline of the lower sacrum and distant from the sacroiliac joint. The probability of invading the sacroiliac joint is relatively low for small-sized chordoma. Moreover, chordoma is a low-malignant and less-invasive tumor. It has a weak ability to invade into the ligamentous portion and the articular cartilage but may invade across the sacroiliac joint via the periarticular tissue.

\section{Conclusions}

In summary, MRI can be used to accurately diagnose transarticular invasion of primary bone tumors abutting the sacroiliac joint. The transarticular invasion incidence of tumors and tumor-like lesions across the sacroiliac joint is associated with pathological type, benignity or malignancy, or the malignant degree of a tumor rather than its location (in the sacrum or ilium). The invasion type of primary bone tumors abutting the sacroiliac joint is not related to the benignity or malignancy or malignant degree of a tumor. Transarticular invasion across the ligamentous portion is quite common. The cartilage portion may serve as a barrier against tumor invasion, but an enlarged tumor can destroy the cartilage to invade into the joint and subsequently cause transarticular invasion.

\section{Abbreviations}

MRI: magnetic resonance imaging

Gd-DTPA: Gadolinium-diethylenetriamine pentaacetic acid

\section{Declarations}

\section{Ethics Approval and Consent to Participate}

The current study was approved by the Institutional Ethics Committee of the First Affiliated Hospital of Sun Yat-Sen University, and the need for signed informed consent was waived. 


\section{Consent for Publication}

We have obtained consent to publish from all the participants.

\section{Availability of data and materials}

The datasets used and analysed during the current study are available from the corresponding author on reasonable request.

\section{Competing interests}

The authors declared that they have no conflict of interest. No authors have received any funding from any institution, including personal relationships, interests, grants, employment, affiliations, patents, inventions, honoraria, consultancies, royalties, stock options/ownership, or expert testimony for the last 12 months.

\section{Funding}

This work was supported by the Medical Scientific Research Foundation of Guangdong Province, China $\triangle N$ o: B2010073 $₫$. Funding supporter played no role in the design of the study and collection, analysis, and interpretation of data and in writing the manuscript.

\section{Authors' Contributions}

LD and JQY participated in design of the study, collected the patients' data, and drafted the manuscript. FLZ, YQW, CYZ processed the figures, helped draft the manuscript, and performed critical revision of the manuscript. ZHG conceived and designed the study, supervised the project. All authors read and approved the final version of the manuscript.

\section{Acknowledgements}

Not applicable.

\section{References}

[1]Chhaya S, White LM, Kandel R, Wunder JS, Ferguson P, Agur A. Transarticular invasion of bone tumours across the sacroiliac joint. Skeletal Radiol. 2005. 34(12): 771-7. 
[2]Ozaki T, Lindner N, Hillmann A, Link T, Winkelmann W. Transarticular invasion of iliopelvic sarcomas into the sacrum. Radiological analysis of 47 cases. Acta Orthop Scand. 1997. 68(4): 381-3.

[3]Abdelwahab IF, Miller TT, Hermann G, Klein MJ, Kenan S, Lewis MM. Transarticular invasion of joints by bone tumors: hypothesis. Skeletal Radiol. 1991. 20(4): 279-83.

[4]Ozaki T, Rodl R, Gosheger G, et al. Sacral infiltration in pelvic sarcomas: joint infiltration analysis II. Clin Orthop Relat Res. 2003. (407): 152-8.

[5]Drnovsek V, Zafiroski G, Brogdon BG, Plavsic BM. Transarticular spread of Ewing's sarcoma across the sacroiliac joint: CT and MRI correlation. Orthopedics. 1999. 22(10): 977-9.

[6]Jordanov MI, Block JJ, Gonzalez AL, Green NE. Transarticular spread of Ewing sarcoma mimicking septic arthritis. Pediatr Radiol. 2009. 39(4): 381-4.

[7]Chong VF, Pathmanathan R, Sambandan SS. Transarticular spread of the sacroiliac joint in a chondrosarcoma. Med J Malaysia. 1994. 49(3): 282-4.

[8]Simon MA, Hecht JD. Invasion of joints by primary bone sarcomas in adults. Cancer. 1982. 50(8): 1649-55.

[9]Quan GM, Ojaimi J, Nadesapillai AP, Zhou H, Choong PF. Resistance of epiphyseal cartilage to invasion by osteosarcoma is likely to be due to expression of antiangiogenic factors. Pathobiology. 2002. 70(6): $361-7$.

[10]Kuettner KE, Pauli BU, Soble L. Morphological studies on the resistance of cartilage to invasion by osteosarcoma cells in vitro and in vivo. Cancer Res. 1978. 38(2): 277-87.

[11]Sorgente N, Kuettner KE, Soble LW, Eisenstein R. The resistance of certain tissues to invasion. II. Evidence for extractable factors in cartilage which inhibit invasion by vascularized mesenchyme. Lab Invest. 1975. 32(2): 217-22.

[12]Eisenstein R, Kuettner KE, Neapolitan C, Soble LW, Sorgente N. The resistance of certain tissues to invasion. III. Cartilage extracts inhibit the growth of fibroblasts and endothelial cells in culture. Am J Pathol. 1975. 81(2): 337-48.

\section{Tables}

Table 1 Transarticular invasion incidence in 128 patients with primary bone tumors and tumor-like lesions near the sacroiliac joint 


\begin{tabular}{cccc}
\hline Tumor type & $\begin{array}{c}\text { Total number } \\
\text { of patients } \\
\text { (Ilium/sacrum) }\end{array}$ & $\begin{array}{c}\text { Number of patients with transarticular } \\
\text { invasion (Ilium/sacrum) }\end{array}$ & $\begin{array}{c}\text { Transarticular invasion } \\
\text { incidence }(\%)\end{array}$ \\
\hline $\begin{array}{c}\text { Conventional } \\
\text { Osteosarcoma } \\
\text { Ewing's sarcoma }\end{array}$ & $16(16 / 2)$ & $15(13 / 2)$ & 51.7 \\
$\begin{array}{c}\text { Central } \\
\text { chondrosarcoma } \\
\text { Chordoma }\end{array}$ & $35(26 / 9)$ & $7(7 / 0)$ & 11.4 \\
$\begin{array}{c}\text { Giant cell tumor of } \\
\text { the bone }\end{array}$ & $20(8 / 12)$ & $4(2 / 2)$ & 7.7 \\
Chondroblastoma & $6(4 / 2)$ & $4(2 / 2)$ & 20.0 \\
Aneurysmal bone & $9(6 / 3)$ & $1(1 / 0)$ & 16.7 \\
cyst & $128(87 / 41)$ & $1(1 / 0)$ & 11.1 \\
Total & $33(26 / 7)$ & & \\
\hline
\end{tabular}

Table 2 Comparison of transarticular invasion incidence between different pathological grades of primary bone tumors and tumor-like lesions near the sacroiliac joint

\begin{tabular}{|c|c|c|c|c|c|}
\hline $\begin{array}{l}\text { Patient } \\
\text { group }\end{array}$ & $\begin{array}{l}\text { Total number } \\
\text { of patients }\end{array}$ & $\begin{array}{l}\text { Number of patients with } \\
\text { transarticular invasion }\end{array}$ & $\begin{array}{l}\text { Transarticular invasion } \\
\text { incidence (\%) }\end{array}$ & $\begin{array}{l}\chi^{2} \text { value between } \\
\text { the groups }\end{array}$ & $\begin{array}{l}\mathrm{P} \text { - } \\
\text { value }\end{array}$ \\
\hline Group & 45 & 22 & 48.9 & Group! vs. 16.68 & प \\
\hline 1 & & & & & 0.01 \\
\hline Group & 48 & 5 & 10.4 & Group $\square$ vs. $\square 0.32$ & $\square$ \\
\hline 2 & & & & & 0.05 \\
\hline Group & 35 & 6 & 17.14 & Group $\square$ vs. $\square 8.72$ & प \\
\hline 3 & & & & & 0.01 \\
\hline
\end{tabular}

Table 3 Transarticular invasion type in 33 patients with primary bone tumors and tumor-like lesions near the sacroiliac joint (cases) 


\begin{tabular}{|c|c|c|c|c|c|c|}
\hline \multirow[t]{3}{*}{ umor type } & $\begin{array}{c}\text { Across the } \\
\text { ligament } \\
\text { portion }\end{array}$ & $\begin{array}{l}\text { Across the } \\
\text { articular } \\
\text { cartilage }\end{array}$ & $\begin{array}{l}\text { Across the } \\
\text { whole joint }\end{array}$ & $\begin{array}{l}\text { Across the } \\
\text { periarticular } \\
\text { tissue }\end{array}$ & $\begin{array}{l}\text { Across the whole } \\
\text { joint and } \\
\text { periarticular tissue }\end{array}$ & Total \\
\hline & Type1 & Type2 & & Type3 & & \\
\hline & & & Туре1+Туре2 & & $\begin{array}{c}\text { Type1+Туре2 } \\
\text { +Туре3 }\end{array}$ & \\
\hline $\begin{array}{l}\text { onventional } \\
\text { teosarcoma }\end{array}$ & 6 & 0 & 5 & 0 & 4 & 15 \\
\hline ng's sarcoma & 4 & 1 & 2 & 0 & 0 & 7 \\
\hline $\begin{array}{l}\text { Central } \\
\text { ndrosarcoma }\end{array}$ & 3 & 0 & 1 & 0 & 0 & 4 \\
\hline Zhordoma & 0 & 0 & 0 & 1 & 0 & 1 \\
\hline $\begin{array}{l}\text { nt cell tumor } \\
\text { if the bone }\end{array}$ & 2 & 0 & 2 & 0 & 0 & 4 \\
\hline ndroblastoma & 1 & 0 & 0 & 0 & 0 & 1 \\
\hline $\begin{array}{l}\text { urysmal bone } \\
\text { cyst }\end{array}$ & 0 & 0 & 0 & 0 & 1 & 1 \\
\hline Total & 16 & 1 & 10 & 1 & 5 & 33 \\
\hline
\end{tabular}

Table 4 Number of individual transarticular invasion types in 33 patients with primary bone tumors and tumorlike lesions near the sacroiliac joint (times)

\begin{tabular}{lcccc}
\hline & Tumor type & (Type 1) & (Type 2) & (Type 3) \\
\hline Group 1 & Conventional osteosarcoma & $100 \%(15 / 15)$ & $60 \%(9 / 15)$ & $26.7 \%(4 / 15)$ \\
& Ewing's sarcoma & $85.7 \%(6 / 7)$ & $42.9 \%(3 / 7)$ & $0(0 / 7)$ \\
Group 2 & Central chondrosarcoma & $100 \%(4 / 4)$ & $25 \%(1 / 4)$ & $0(0 / 4)$ \\
& Chordoma & $0(0 / 1)$ & $0(0 / 1)$ & $100 \%(1 / 1)$ \\
Group 3 & Giant cell tumor of the bone & $100 \%(4 / 4)$ & $25 \%(1 / 4)$ & $0(0 / 4)$ \\
& Chondroblastoma & $100 \%(1 / 1)$ & $0(0 / 1)$ & $0(0 / 1)$ \\
& Aneurysmal bone cyst & $100 \%(1 / 1)$ & $100 \%(1 / 1)$ & $0(0 / 1)$ \\
Total & & $93.9 \%(31 / 33)$ & $45.5 \%(15 / 33)$ & $15.2 \%(5 / 33)$ \\
\hline
\end{tabular}

\section{Figures}




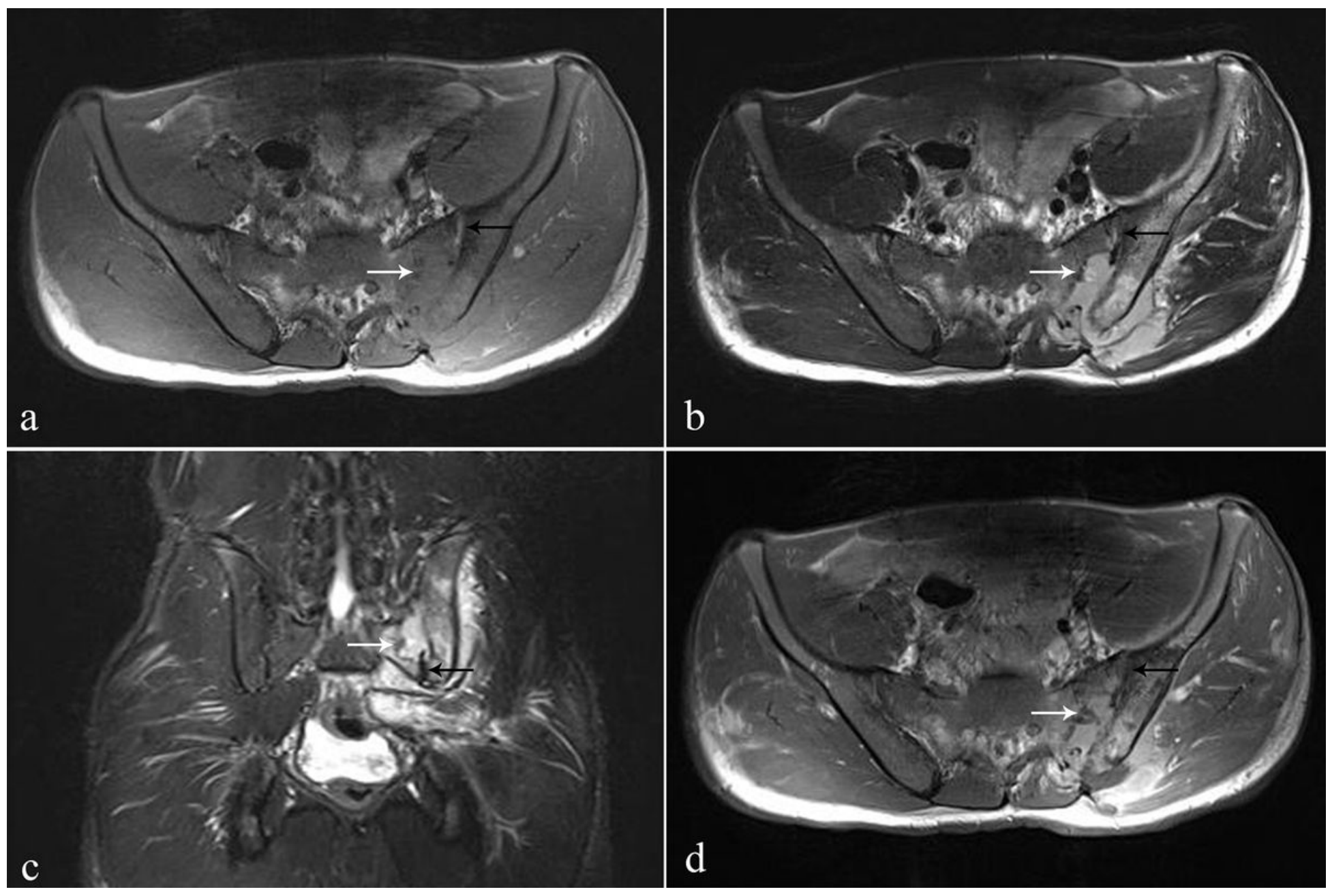

\section{Figure 1}

An 18-year-old male with left iliac Ewing's sarcoma presenting transarticular invasion of the sacrum across the ligamentous portion, which was confirmed by surgical findings. MR T1WI (a), T2WI (b), T2WI with fat suppression (c), and enhanced T1WI (d) showed tumor invasion of the sacrum (white arrow) across the posterior sacroiliac joint (ligamentous portion); the posterior space of the sacroiliac joint and the left portion of the sacrum was filled with tumor tissue with intermediate signal intensity on T1WI and high signal intensity on T2WI. Tumor signals were not observed in the anterior-inferior space (cartilage portion) of the sacroiliac joint (red arrow).
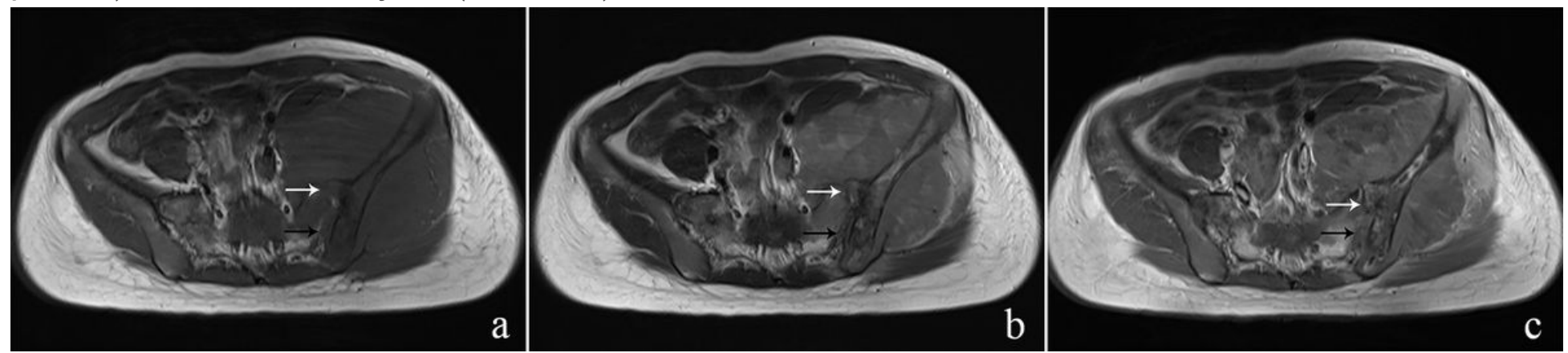

Figure 2 
A 15-year-old female with left iliac Ewing's sarcoma presenting transarticular invasion of the sacrum across the articular cartilage, which was confirmed by surgical findings. MR T1WI (a), T2WI (b), and enhanced T1WI (c) showed tumor invasion of the sacroiliac joint across the anterior portion (cartilage) of the joint, in which the lateral articular surface of the sacrum was destroyed (white arrow). A soft tissue density mass was observed at the posterior space (ligamentous portion), but the sacral cortical portion exhibited a normal signal (red arrow).

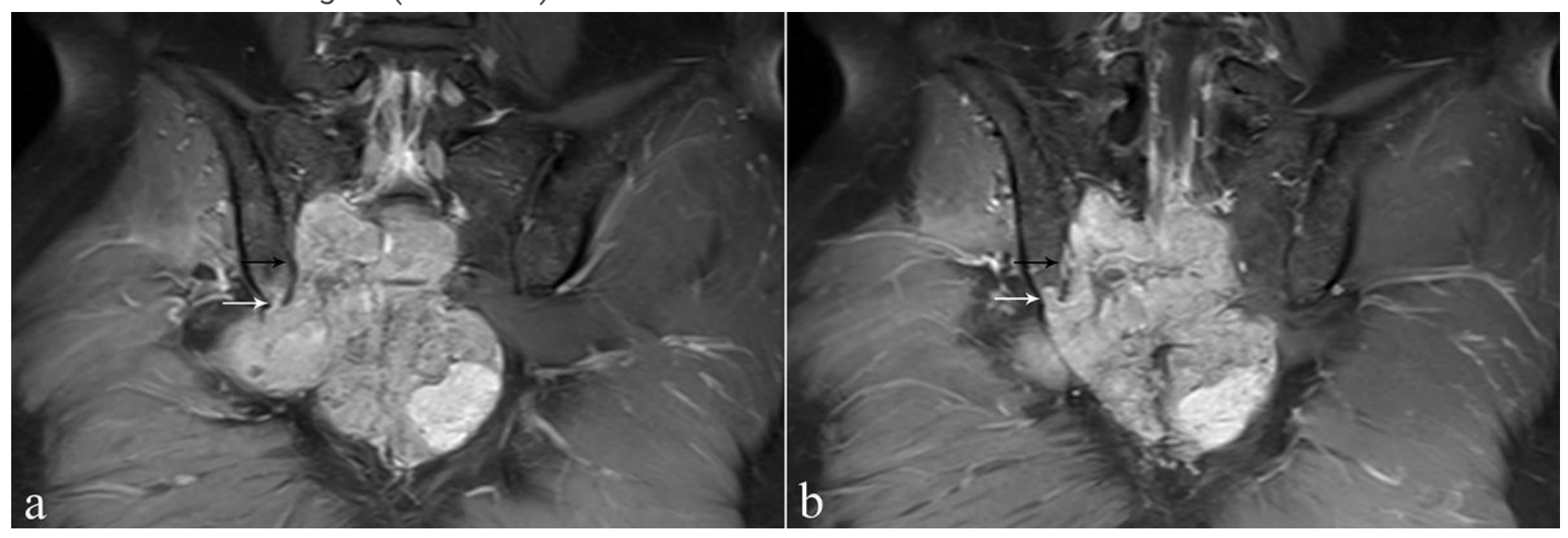

\section{Figure 3}

A 38-year-old male with sacral chordoma presenting transarticular invasion of the ilium across the periarticular space, which was confirmed by surgical findings. MR enhanced T1WI $(a, b)$ showed tumor invasion of the right ilium across the inferior portion of the sacroiliac joint (white arrow), and the cortical bone of the articular surface in the sacrum was interrupted. Tumor tissue was observed at the joint space, but the cortical bone signal of the right ilium was not interrupted (red arrow). 


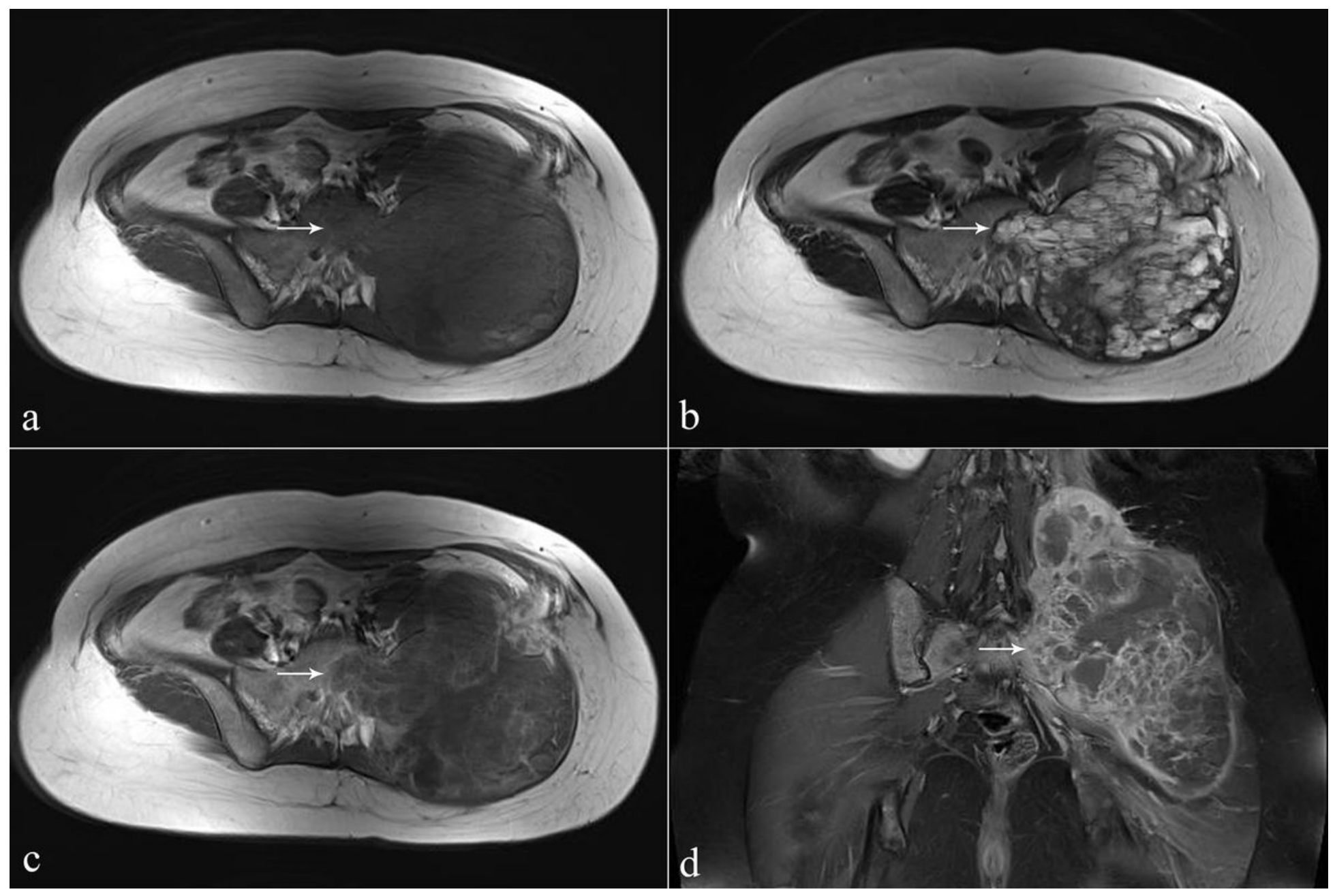

\section{Figure 4}

A 36-year-old female with giant bone cell tumor of the left ilium combined with an aneurysmal bone cyst presenting invasion of the sacrum across the whole left sacroiliac joint (including cartilage and ligamentous portions), which was confirmed by surgical findings. MR T1WI (a), T2WI (b), enhanced T1WI (c), and enhanced T1WI with fat suppression (d) showed tumor invasion of the sacrum across the whole left sacroiliac joint (white arrow). 